\title{
ATF3 rSNPs, transcriptional factor binding sites and human etiology ${ }^{*}$
}

\author{
Norman E. Buroker
}

Department of Pediatrics, University of Washington, Seattle, USA

Email: nburoker@u.washington.edu

Received 26 September 2013; revised 25 October 2013; accepted 15 November 2013

Copyright (C) 2013 Norman E. Buroker. This is an open access article distributed under the Creative Commons Attribution License, which permits unrestricted use, distribution, and reproduction in any medium, provided the original work is properly cited.

\begin{abstract}
Three rSNPs (rs3125289, rs1877474 and rs11119982) in one intron of the activating transcription factor 3 (ATF3) gene have been significantly associated with the human etiology of hypospadias and may be associated with human disease. These rSNP alleles alter the DNA landscape for potential transcriptional factors (TFs) to attach resulting in changes in transcriptional factor binding sites (TFBS). These TFBS changes are examined with respect to the human etiology of hypospadias which has been found to be significantly associated with the rSNPs.
\end{abstract}

Keywords: ATF3; rSNPs; TFBS; Human Etiology

\section{INTRODUCTION}

The activating transcription factor 3 (ATF3) gene is a member of the activating transcription factor/cAMP responsive element binding (CREB) protein family of transcription factors, which share the basic region-leucine zipper (bZip) DNA binding motif (TGACGTCA). This gene is induced by a variety of signals including many of those encountered by cancer cells, and is involved in the complex process of cellular stress response [1-3]. ATF3 has been viewed as a hub of the cellular adaptive response network which allows cells adapt to disturbances in homeostasis [4]. This gene has been shown to be up-regulated during sexual differentiation [5] which indicates a potential role in hypospadias. Three unlinked ATF3 SNPs (rs3125289, rs1877474 and rs 11119982) which span a $16 \mathrm{~kb}$ region of intron one have been independently found to be significantly associated with the risk of hypospadias [6]. This suggests that these SNPs in intron one may be part of a regulatory region for the ATF3 gene. To follow up on this possibility, the SNPs were examined for associations to potential

"Conflict of interest statement: The author declares that there is no conflict of interests. transcription factor binding sites (TFBS).

Single nucleotide changes that affect gene expression by impacting gene regulatory sequences such as promoters, enhancers, and silencers are known as regulatory SNPs (rSNPs) [7-10]. A rSNPs within a transcriptional factor binding site (TFBS) can change a transcriptional factor's (TF) ability to bind its TFBS [11-14], in which case the TF would be unable to effectively regulate its target gene [15-19]. This concept is examined for the above ATF3 SNPs of intron one and their allelic association with TFBS. In this report, I discuss these SNP associations with changes in potential TFBS and their possible relationship to human etiology.

\section{MATERIALS AND METHODS}

\section{Identifying TFBS}

The JASPAR CORE database [20,21] and ConSite [22] were used to identify the TFBS in this study. JASPAR is a collection of transcription factor DNA-binding preferencesused for scanning genomic sequences where ConSite is a web-based tool for finding cis-regulatory elements in genomic sequences. The Vector NTI Advance 11 computer program (Invitrogen, Life Technologies) was used to locate the TFBS in the ATF3 gene (NCBI Ref Seq NM_001674) from $51 \mathrm{~kb}$ upstream of the transcriptional start site to $766 \mathrm{bp}$ past the $3^{\prime}$ UTR which represents a total of $57.6 \mathrm{Kbp}$. The JASPAR CORE database was also used to compute each nucleotide occurrence (\%) within the TFBS where upper case lettering indicate that the nucleotide occurs $90 \%$ or greater and lower case less than $90 \%$. The occurrence of each SNP allele in the TFBS is also computed from the database (Table 1 \& Supplement).

\section{RESULTS}

\section{ATF3 rSNPs and TFBS}

The ATF3 gene encodes a member of the mammalian 
Table 1. The ATF3 SNPs from intron 1 that were examined in this study. Also listed are the transcriptional factors (TF), their potential binding sites (TFBS) containing these SNPs and DNA strand orientation. TFs in red differ between the rSNP alleles. Where upper case nucleotide designates the $90 \%$ conserved BS region and red is the SNP location of the alleles in the TFBS. Below the TFBS is the nucleotide occurrence (\%) obtained from the Jaspar Core database. Also listed are the numbers (\#) of binding sites in the gene for the given TF. Note: TFs can bind to more than one nucleotide sequence.

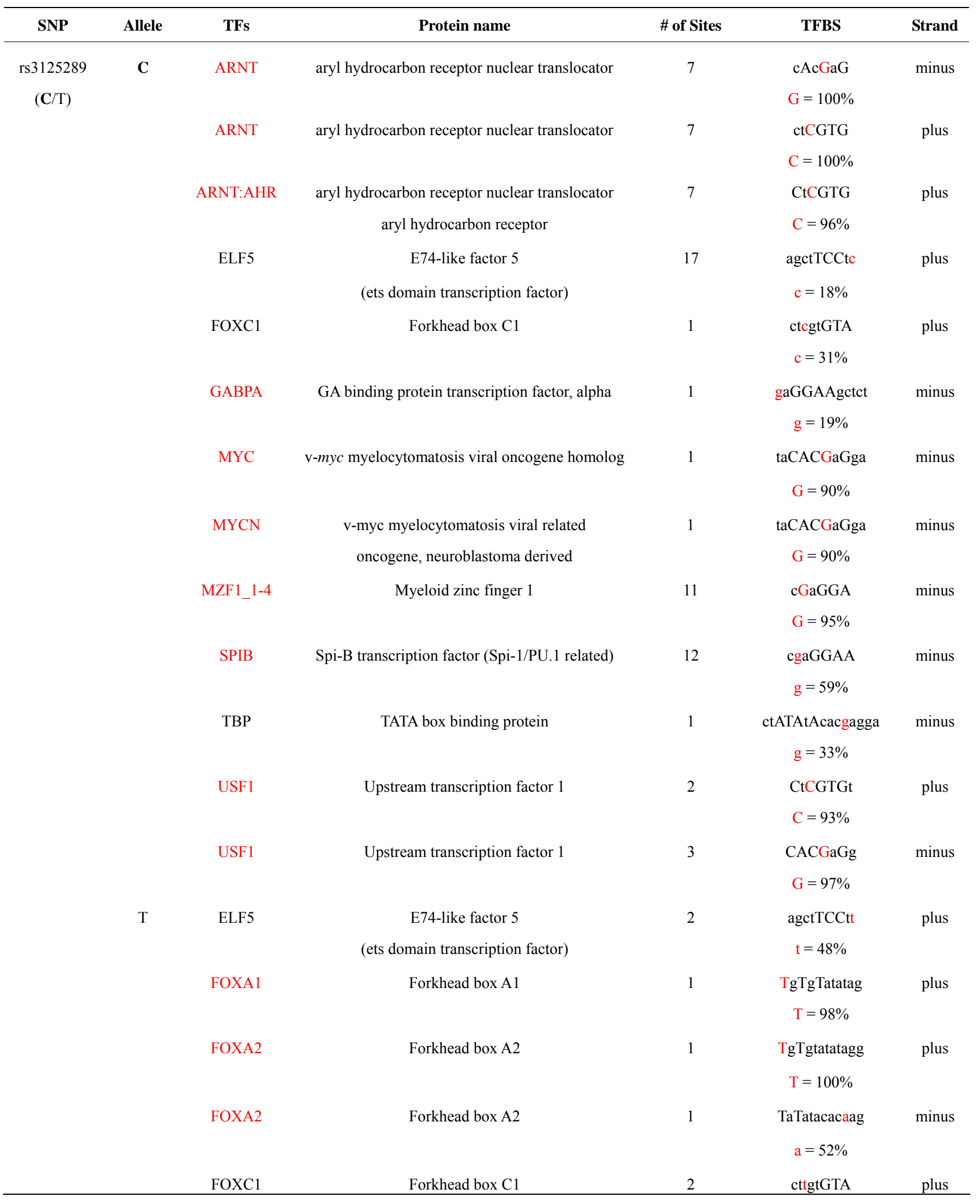




\begin{tabular}{|c|c|c|c|c|c|c|}
\hline & & & & & $\mathrm{t}=31 \%$ & \\
\hline & & FOXL1 & Forkhead box L1 & 5 & $\operatorname{tgtgtATA}$ & plus \\
\hline & & & & & $\mathrm{t}=48 \%$ & \\
\hline & & FOXL1 & Forkhead box L1 & 5 & tatacAcA & minus \\
\hline & & & & & $A=96 \%$ & \\
\hline & & FOXO3 & Forkhead box O3 & 5 & tatAcACA & minus \\
\hline & & & & & $A=92 \%$ & \\
\hline & & HLTF & Helicase-like transcription factor & 2 & ttcCtTgtgt & plus \\
\hline & & & & & $\mathrm{T}=100 \%$ & \\
\hline & & SOX10 & SRY (sex determining region Y)-box 10 & 27 & $\operatorname{cctTgT}$ & plus \\
\hline & & & & & $\mathrm{T}=100 \%$ & \\
\hline & & SOX10 & SRY (sex determining region Y)-box 10 & 50 & $\operatorname{ttg} \operatorname{Tg} \mathrm{T}$ & plus \\
\hline & & & & & $\mathrm{t}=45 \%$ & \\
\hline & & SOX17 & SRY (sex determining region Y)-box 17 & 4 & ttccTTGTg & plus \\
\hline & & & & & $\mathrm{T}=100 \%$ & \\
\hline & & SRY & Sex determining region $\mathrm{Y}$ & 1 & gtagACAAt & minus \\
\hline & & & & & $A=100 \%$ & \\
\hline & & ТВР & TATA box binding protein & 1 & ctATAtAcacaagga & minus \\
\hline & & & & & $a=22 \%$ & \\
\hline \multirow{14}{*}{$\begin{array}{c}\text { rs1877474 } \\
(\mathbf{C} / \mathrm{T})\end{array}$} & $\mathbf{C}$ & HLTF & Helicase-like transcription factor & 7 & $\operatorname{agcCtTttcg}$ & plus \\
\hline & & & & & $c=24 \%$ & \\
\hline & & SPIB & Spi-B transcription factor (Spi-1/PU.1 related) & 12 & $\operatorname{agcGaAA}$ & minus \\
\hline & & & & & $\mathrm{G}=96 \%$ & \\
\hline & $\mathrm{T}$ & ETS1 & Protein C-ets-1 & 54 & $\mathrm{tt} \mathrm{TgCt}$ & plus \\
\hline & & & & & $\mathrm{T}=98 \%$ & \\
\hline & & HLTF & Helicase-like transcription factor & 1 & agcCtTtttg & plus \\
\hline & & & & & $t=14 \%$ & \\
\hline & & FOXA1 & Forkhead box A1 & 1 & TtTTTgCtctg & plus \\
\hline & & & & & $\mathrm{T}=91 \%$ & \\
\hline & & SOX10 & SRY (sex determining region Y)-box 10 & 119 & $\operatorname{cttTtT}$ & plus \\
\hline & & & & & $\mathrm{T}=95 \%$ & \\
\hline & & SPIB & Spi-B transcription factor (Spi-1/PU.1 related) & 12 & acaGcAA & minus \\
\hline & & & & & $A=98 \%$ & \\
\hline \multirow{5}{*}{$\begin{array}{l}\text { rs11119982 } \\
\text { (C/T) }\end{array}$} & $\mathbf{C}$ & ARNT:AHR & aryl hydrocarbon receptor nuclear translocator & 10 & cGaGTG & minus \\
\hline & & & aryl hydrocarbon receptor & & $G=96 \%$ & \\
\hline & & GATA2 & GATA binding protein 2 & 23 & cGATg & plus \\
\hline & & & & & $c=25 \%$ & \\
\hline & & GATA3 & GATA binding protein 3 & 4 & cGATgg & plus \\
\hline
\end{tabular}


HLTF

Helicase-like transcription factor

NKX3-2

PAX2

TFAP2A

$\mathrm{T}$

Natural killer 3 homeobox 2

Paired box gene 2
Transcription factor AP-2 alpha

(activating enhancer binding protein 2 alpha)

AT rich interactive domain 3A (BRIGHT-like)

ARNT

aryl hydrocarbon receptor nuclear translocator

ARNT

aryl hydrocarbon receptor nuclear translocator

GATA2

GATA3

MAX

MYB

NKX2-5

NKX3-2

PAX2

PAX2

TFAP2A

USF1

USF1

ZEB1
GATA binding protein 2

GATA binding protein 3

MYC associated factor $\mathrm{X}$

v-myb myeloblastosis viral oncogene homolog

Natural killer 2 homeobox 5

Natural killer 3 homeobox 2

Paired box gene 2

Transcription factor AP-2 alpha

(activating enhancer binding protein 2 alpha)

upstream transcription factor 1

upstream transcription factor 1

Zinc finger E-box binding homeobox 1
Paired box gene 2 $\mathrm{c}=22 \%$

1

ggcCaTcgag

minus

$\mathrm{g}=37 \%$

tcgAGTgtc minus

$\mathrm{g}=13 \%$

agaCActc

plus

$\mathrm{c}=35 \%$

1

GCCatcgag

minus

$\mathrm{G}=43 \%$

ATcAAg minus

$A=100 \%$

cAaGTG minus

$A=95 \%$

cActTG

plus

$A=100 \%$

136

tGATg plus

$\mathrm{t}=17 \%$

tGATgg

plus

$\mathrm{t}=32 \%$

5

agaCACtTGa plus

$\mathrm{T}=100 \%$

gaCacTTg plus

$\mathrm{T}=100 \%$

tcAAgtg minus

$\mathrm{A}=100 \%$

tcaAGTgtc minus

$\mathrm{a}=8 \%$

agaCactt

plus

$t=26 \%$

catCaagt minus

$\mathrm{a}=84 \%$

GCCatcaag minus

$\mathrm{a}=29 \%$

CAaGTGt minus

$\mathrm{A}=100 \%$

CACtTGa plus

$\mathrm{T}=93 \%$

33
cACTTg plus

$\mathrm{T}=98 \%$ 
activation transcription factor/cAMP responsive elementbinding (CREB) protein family of transcription factors. This gene is one of seven ATFs that influence cellular physiologic processes by regulating the expression of downstream target genes, which are related to growth, survival, and other cellular activities. The three ATF3 rSNPs [rs3125289 (C/T), rs1877474 (C/T) and rs$11119982(\mathrm{C} / \mathrm{T})]$ in intron one has been found to be significantly associated with the risk of hypospadias [6]. The rs3125289 and rs1877474 AFT3-T alleles have a significantly greater occurrence in the case subjects compared to the corresponding control group where the rs11119982 ATF3-C allele has a significantly greater advantage [6].

The rs3125289 ATF3-C allele creates eight unique TFBS for the ARNT, ARNT:AHR, GABPA, MYC, MYCN, MZF1_1-4, SPIB and USF1 TFs which are involved in xenobiotic metabolism, cell cycle progression, apoptosis, cellular transformation, a variety of tumors, lymphoid-specific enhancer and cellular transcription, respectively (Table 1). The rs3125289 ATF3-T allele also creates eight unique TFBS for the FOXA1 \& 2, FOXL1, FOXO3, HLTF, SOX10 \& 17 and SRY TFs which are involved in embryonic development, apoptosis, chromatin structure, cell fate and male development, respectively (Table $1 \&$ Supplement). Three TFBS have been conserved between the two rs3125289 alleles which are for the ELF4, FOXC1 and TBP TFs that regulate epithelium-specific genes, resistance to oxidative stress and a core factor in DNA binding for TFIID, respectively (Table 1).

The rs1877474 AFT3-C allele creates no unique TFBS while the AFT3-T allele creates three unique TFBS which are for the ETS1, FOXA1 and SOX10 TFs which interact with TTRAP, UBE2I and Death associated proteins and regulates embryonic development, respectively (Table 1). Two TFBS have been conserved between the two alleles which are HLTF and SPIB TFs that are involved in altering chromatin structure and act as a lymphoid-specific enhancer, respectively (Table 1).

The rs11119982 ATF3-C allele creates one unique TFBS for the HLTF TF which is involved with altering chromatin structure. The ATF3-T allele creates five unique TFBS for the ARID3A, MAX, MYB, USF1 and ZEB1 TFs. These TFs are involved with the AT-rich interaction domain, transcription regulation, hematopoietic progenitor cells control, cellular transcription and repression, respectively (Table 1). Eight TFBS have been conserved between the two alleles which are ARNT, ARNT: AHR, GATA2 \& 3, HKX2 \& 3, PAX2 and TFAP2A TFs that are involved with xenobiotic metabolism, hematopoietic and endocrine cell lineages, endothelial cell boilogy, transcription repression, kidney cell differentiation and transcription activation, respectively (Table 1).

\section{DISCUSSION}

GWAS over the last decade have identified nearly 6500 disease or trait-predisposing SNPs where only 7\% of these are located in protein-coding regions of the genome $[23,24]$ and the remaining $93 \%$ are located within noncoding areas $[25,26]$ such as regulatory or intergenic regions. SNPs which occur in the putative regulatory region of a gene where a single base change in the DNA sequence of a potential TFBS may affect the process of gene expression, which are drawing more attention [7, $9,27]$. A SNP in a TFBS can have multiple consequences. Often the SNP does not change the TFBS interaction nor does it alter gene expression since a transcriptional factor (TF) will usually recognize a number of different binding sites in the gene. In some cases, the SNP may increase or decrease the TF binding which results in allele-specific gene expression. In rare cases, a SNP may eliminate the natural binding site or generate a new binding site. In the cases, the gene is no longer regulated by the original TF. Therefore, functional rSNPs in TFBS may result in differences in gene expression, phenotypes and susceptibility to environmental exposure [27]. Examples of rSNPs associated with disease susceptibility are numerous and several reviews have been published [27-30].

In this report, the rs3125289 ATF3-C allele [C (+ strand) or G (-strand)] located in the ARNT and ARNT: AHR TFBS has a $100 \%$ and $96 \%$ occurrence, respectively, in humans; however, these BS occurs seven times in the gene and therefore a change in the TFBS created by the rSNP would probably not have any impact on the regulation of the gene (Table $1 \&$ Supplement). The ATF3-C allele is also located in the MYC and MYCN TFBS with a $90 \%$ occurrence and this BS occurs only once in the gene and therefore a nucleotide change created by the rSNP on these TFBS would probably have an impact on the regulation of the gene. The rs 3125289 ATF3-T allele located in the FOXA2 and SRY TFBS has a $100 \%$ occurrence in humans and each BS occurs only once in the gene; therefore, the rSNP would probably have an impact on the regulation of the gene. Since the SRY TF located on the Y chromosome is a transcriptional regulator that controls a genetic switch in male development, this rSNP might be expected to have an impact on male etiology as has been shown to be the case with its risk of hypospadias [6].

The rs1877474 ATF3-T allele [A (-strand) or T (+ strand)] located in the FOXA1 TFBS has an occurrence of $91 \%$ in humans and this BS occurs only once in the gene and thereby might have an impact on embryonic development and tissue differentiation (Table 1). The other two unique TFBS (ETS1 and SOX10) occur multiple times in the gene and would not be expected to have an impact on gene regulation. The rs1877474 ATF3-C 
allele does not have any unique TFBS and therefore would not be expected to have any impact on gene regulation.

The rs11119982 ATF3-C allele [C (+strand) or G (strand)] located in the HLTF TFBS has an occurrence of $37 \%$ in humans (table). While this BS motif occurs only once in the gene and other HLTF BS motifs are found in intron one, it is doubtful that a change in the BS created by the rSNP would have an impaction on gene regulation. The rs11119982 ATF3-T allele located in the MYB TFBS has a $100 \%$ nucleotide occurrence for that BS motif in humans and occurs only once in the gene and thereby may have an impact on gene regulation and in the control of proliferation and differentiation of hematopoietic progenitor cells. Other rs11119982 ATF3-T allele unique TFBS affected by this rSNP occur multiple times in the gene and would probably have little effect on gene regulation. Since each of these rSNPs can alter TFBS in ATF3 intron one, it is easy to understand why the rSNPs have been found to independently affect the risk of hypospadias [6].

Human diseases or conditions that have been significantly associated with these rSNPs of the ATF3 gene are shown in the table along with rSNP allele-specific TFBS. What a change in the rSNP alleles can do, is to alter the DNA landscape around the SNP for potential TFs to attach and regulate a gene. This change in the regulatory landscape can alter gene regulation which in turn can result in human disease, a change in condition or illness. In this report, three intron one rSNPs of the ATF3 gene have been described to illustrate that a change in rSNP alleles can provide different TFBS which in turn are also significantly associated with human etiology.

\section{REFERENCES}

[1] Chen, B.P., Liang, G., Whelan, J. and Hai, T. (1994) ATF3 and ATF3 delta Zip. Transcriptional repression versus activation by alternatively spliced isoforms. The Journal of Biological Chemistry, 269, 15819-15826.

[2] Hai, T. and Hartman, M.G. (2001) The molecular biology and nomenclature of the activating transcription factor/cAMP responsive element binding family of transcription factors: Activating transcription factor proteins and homeostasis. Gene, 273, 1-11.

http://dx.doi.org/10.1016/S0378-1119(01)00551-0

[3] Thompson, M.R., Xu, D. and Williams, B.R. (2009) ATF3 transcription factor and its emerging roles in immunity and cancer. Journal of Molecular Medicine, 87, 1053-1060. http://dx.doi.org/10.1007/s00109-009-0520-x

[4] Hai, T., Wolford, C.C. and Chang, Y.S. (2010) ATF3, a hub of the cellular adaptive-response network, in the pathogenesis of diseases: is modulation of inflammation a unifying component? Gene Expression, 15, 1-11. http://dx.doi.org/10.3727/105221610X12819686555015

[5] Liu, B., Agras, K., Willingham, E., Vilela, M.L. and
Baskin, L.S. (2006) Activating transcription factor 3 is estrogen-responsive in utero and upregulated during sexual differentiation. Hormone Research, 65, 217-222. http://dx.doi.org/10.1159/000092402

[6] Beleza-Meireles, A., Tohonen, V., Soderhall, C., Schwentner, C., Radmayr, C., Kockum, I. and Nordenskjold, A. (2008) Activating transcription factor 3: A hormone responsive gene in the etiology of hypospadias. European Journal of Endocrinology, 158, 729-739.

http://dx.doi.org/10.1530/EJE-07-0793

[7] Knight, J.C. (2003) Functional implications of genetic variation in non-coding DNA for disease susceptibility and gene regulation. Clinical Science, 104, 493-501. http://dx.doi.org/10.1042/CS20020304

[8] Knight, J.C. (2005) Regulatory polymorphisms underlying complex disease traits. Journal of Molecular Medicine, 83, 97-109. http://dx.doi.org/10.1007/s00109-004-0603-7

[9] Wang, X., Tomso, D.J., Liu, X. and Bell, D.A. (2005) Single nucleotide polymorphism in transcriptional regulatory regions and expression of environmentally responsive genes. Toxicology and Applied Pharmacology, 207, 84-90. http://dx.doi.org/10.1016/j.taap.2004.09.024

[10] Wang, X., Tomso, D.J., Chorley, B.N., Cho, H.Y., Cheung, V.G., Kleeberger, S.R. and Bell, D.A. (2007) Identification of polymorphic antioxidant response elements in the human genome. Human Molecular Genetics, 16, 1188-1200. http://dx.doi.org/10.1093/hmg/ddm066

[11] Claessens, F., Verrijdt, G., Schoenmakers, E., Haelens, A., Peeters, B., Verhoeven, G. and Rombauts, W. (2001) Selective DNA binding by the androgen receptor as a mechanism for hormone-specific gene regulation. The Journal of Steroid Biochemistry and Molecular Biology, 76, 23-30.

http://dx.doi.org/10.1016/S0960-0760(00)00154-0

[12] Hsu, M.H., Savas, U., Griffin, K.J. and Johnson, E.F. (2007) Regulation of human cytochrome P450 4F2 expression by sterol regulatory element-binding protein and lovastatin. The Journal of Biological Chemistry, 282, 5225-5236.

http://dx.doi.org/10.1074/jbc.M608176200

[13] Takai, H., Araki, S., Mezawa, M., Kim, D.S., Li, X., Yang, L., Li, Z., Wang, Z., Nakayama, Y. and Ogata, Y. (2008) AP1 binding site is another target of FGF2 regulation of bone sialoprotein gene transcription. Gene, 410, 97-104. http://dx.doi.org/10.1016/j.gene.2007.11.017

[14] Buroker, N.E., Huang, J.Y., Barboza, J., Ledee, D.R., Eastman, R.J., Jr., Reinecke, H., Ning, X.H., Bassuk, J.A. and Portman, M.A. (2012) The adaptor-related protein complex 2, alpha 2 subunit (AP2alpha2) gene is a peroxisome proliferator-activated receptor cardiac target gene. The Protein Journal, 31, 75-83. http://dx.doi.org/10.1007/s10930-011-9379-0

[15] Huang, C.N., Huang, S.P., Pao, J.B., Hour, T.C., Chang, T.Y., Lan, Y.H., Lu, T.L., Lee, H.Z., Juang, S.H., Wu, P.P., Huang, C.Y., Hsieh, C.J. and Bao, B.Y. (2012) Genetic polymorphisms in oestrogen receptor-binding sites affect clinical outcomes in patients with prostate cancer receiving androgen-deprivation therapy. Journal of Inter- 
nal Medicine, 271, 499-509.

http://dx.doi.org/10.1111/j.1365-2796.2011.02449.x

[16] Huang, C.N., Huang, S.P., Pao, J.B., Chang, T.Y., Lan, Y.H., Lu, T.L., Lee, H.Z., Juang, S.H., Wu, P.P., Pu, Y.S., Hsieh, C.J. and Bao, B.Y. (2012) Genetic polymorphisms in androgen receptor-binding sites predict survival in prostate cancer patients receiving androgen-deprivation therapy. Annals of Oncology, 23, 707-713. http://dx.doi.org/10.1093/annonc/mdr264

[17] Yu, B., Lin, H., Yang, L., Chen, K., Luo, H., Liu, J., Gao, X., Xia, X. and Huang, Z. (2012) Genetic variation in the $\mathrm{Nrf} 2$ promoter associates with defective spermatogenesis in humans. Journal of Molecular Medicine.

[18] Wu, J., Richards, M.H., Huang, J., Al-Harthi, L., Xu, X., Lin, R., Xie, F., Gibson, A.W., Edberg, J.C. and Kimberly, R.P. (2011) Human FasL gene is a target of betacatenin/T-cell factor pathway and complex FasL haplotypes alter promoter functions. PLoS One, 6, e26143. http://dx.doi.org/10.1371/journal.pone.0026143

[19] Alam, M., Pravica, V., Fryer, A.A., Hawkins, C.P. and Hutchinson, I.V. (2005) Novel polymorphism in the promoter region of the human nerve growth-factor gene. International Journal of Immunogenetics, 32, 379-382. http://dx.doi.org/10.1111/j.1744-313X.2005.00541.x

[20] Bryne, J.C., Valen, E., Tang, M.H., Marstrand, T., Winther, O., da Piedade, I., Krogh, A., Lenhard, B. and Sandelin, A. (2008) JASPAR, the open access database of transcription factor-binding profiles: New content and tools in the 2008 update. Nucleic Acids Research, 36D, 102-106. http://dx.doi.org/10.1093/nar/gkm955

[21] Sandelin, A., Alkema, W., Engstrom, P., Wasserman, W.W. and Lenhard, B. (2004) JASPAR: An open-access database for eukaryotic transcription factor binding profiles. Nucleic Acids Research, 32D, 91-94. http://dx.doi.org/10.1093/nar/gkh012

[22] Sandelin, A., Wasserman, W.W. and Lenhard, B. (2004) ConSite: web-based prediction of regulatory elements using cross-species comparison. Nucleic Acids Research, 32, W249-252.

[23] Pennisi, E. (2011) The Biology of Genomes. Disease risk links to gene regulation. Science, 332, 1031. http://dx.doi.org/10.1126/science.332.6033.1031
[24] Kumar, V., Wijmenga, C. and Withoff, S. (2012) From genome-wide association studies to disease mechanisms: Celiac disease as a model for autoimmune diseases. Seminars in Immunopathology, 34, 567-580. http://dx.doi.org/10.1007/s00281-012-0312-1

[25] Hindorff, L.A., Sethupathy, P., Junkins, H.A., Ramos, E.M., Mehta, J.P., Collins, F.S. and Manolio, T.A. (2009) Potential etiologic and functional implications of genome-wide association loci for human diseases and traits. Proceedings of the National Academy of Sciences, 106, 9362-9367. http://dx.doi.org/10.1073/pnas.0903103106

[26] Kumar, V., Westra, H.J., Karjalainen, J., Zhernakova, D.V., Esko, T., Hrdlickova, B., Almeida, R., Zhernakova, A., Reinmaa, E., Vosa, U., Hofker, M.H., Fehrmann, R.S., $\mathrm{Fu}$, J., Withoff, S., Metspalu, A., Franke, L. and Wijmenga, C. (2013) Human disease-associated genetic variation impacts large intergenic non-coding RNA expression. PLoS Genetics, 9, e1003201. http://dx.doi.org/10.1371/journal.pgen.1003201

[27] Chorley, B.N., Wang, X., Campbell, M.R., Pittman, G.S., Noureddine, M.A. and Bell, D.A. (2008) Discovery and verification of functional single nucleotide polymerphisms in regulatory genomic regions: current and developing technologies. Mutation Research, 659, 147-157. http://dx.doi.org/10.1016/j.mrrev.2008.05.001

[28] Prokunina, L. and Alarcon-Riquelme, M.E. (2004) Regulatory SNPs in complex diseases: Their identification and functional validation. Expert Reviews in Molecular Medicine, 6, 1-15. http://dx.doi.org/10.1017/S1462399404007690

[29] Buckland, P.R. (2006) The importance and identification of regulatory polymorphisms and their mechanisms of action. Biochimica et Biophysica Acta, 1762, 17-28. http://dx.doi.org/10.1016/j.bbadis.2005.10.004

[30] Sadee, W., Wang, D., Papp, A.C., Pinsonneault, J.K., Smith, R.M., Moyer, R.A. and Johnson, A.D. (2011) Pharmacogenomics of the RNA world: Structural RNA polymorphisms in drug therapy. Clinical Pharmacology \& Therapeutics, 89, 355-365.

http://dx.doi.org/10.1038/clpt.2010.314 
Supplement. TF discription.

\begin{tabular}{|c|c|}
\hline TFs & TF discription \\
\hline ARID3A & This gene encodes a member of the ARID (AT-rich interaction domain) family of DNA binding proteins. \\
\hline ARNT & Involved in the induction of several enzymes that participate in xenobiotic metabolism. \\
\hline ARNT:AHR & $\begin{array}{l}\text { The dimer alters transcription of target genes. Involved in the induction } \\
\text { of several enzymes that participate in xenobiotic metabolism. }\end{array}$ \\
\hline ETS1 & $\begin{array}{l}\text { The protein encoded by this gene belongs to the ETS family of transcription factors and has been shown to interact with } \\
\text { TTRAP, UBE2I and Death associated proteins. }\end{array}$ \\
\hline FOXA1 & $\begin{array}{l}\text { Transcription factor that is involved in embryonic development, establishment of tissue-specific gene } \\
\text { expression and regulation of gene expression in differentiated tissues. }\end{array}$ \\
\hline FOXC1 & $\begin{array}{l}\text { This gene belongs to the forkhead family of transcription factors which is characterized by a distinct DNA-binding forkhead } \\
\text { domain. An important regulator of cell viability and resistance to oxidative stress. }\end{array}$ \\
\hline FOXL1 & This gene encodes a member of the forkhead/winged helix-box (FOX) family of transcription factors. \\
\hline FOXO3 & $\begin{array}{l}\text { This gene belongs to the forkhead family of transcription factors which are characterized by a distinct forkhead domain. } \\
\text { This gene likely functions as a trigger for apoptosis through expression of genes necessary for cell death. }\end{array}$ \\
\hline GABPA & This gene encodes one of three GA-binding protein transcription factor subunits which functions as a DNA-binding subunit. \\
\hline GATA2 & $\begin{array}{l}\text { A member of the GATA family of zinc-finger transcription factors that are named for the consensus nucleotide sequence } \\
\text { they bind in the promoter regions of target genes and play an essential role in regulating transcription of genes } \\
\text { involved in the development and proliferation of hematopoietic and endocrine cell lineages. }\end{array}$ \\
\hline GATA3 & Plays an important role in endothelial cell biology. \\
\hline MAX & $\begin{array}{l}\text { The protein encoded by this gene is a member of the basic helix-loop-helix leucine } \\
\text { zipper (bHLHZ) family of transcription factors. Transcription regulator. }\end{array}$ \\
\hline MYB & $\begin{array}{l}\text { This gene encodes a transcription factor that is a member of the MYB family of transcription factor genes. Transcriptional } \\
\text { activator and plays an important role in the control of proliferation and differentiation of hematopoietic progenitor cells. }\end{array}$ \\
\hline MYC & $\begin{array}{l}\text { The protein encoded by this gene is a multifunctional, nuclear phosphoprotein that plays a role } \\
\text { in cell cycle progression, apoptosis and cellular transformation. }\end{array}$ \\
\hline MYCN & $\begin{array}{l}\text { This gene is a member of the MYC family and encodes a protein with a basic helix-loop-helix (bHLH) domain. } \\
\text { Amplification of this gene is associated with a variety of tumors, most notably neuroblastomas. }\end{array}$ \\
\hline MZF1_1-4 & Trancription regulator \\
\hline NKX2-5 & $\begin{array}{l}\text { This gene encodes a member of the NK family of homeobox-containing proteins. Transcriptional repressor } \\
\text { that acts as a negative regulator of chondrocyte maturation. }\end{array}$ \\
\hline NKX3-2 & $\begin{array}{l}\text { This gene encodes a member of the NK family of homeobox-containing proteins. Transcriptional repressor } \\
\text { that acts as a negative regulator of chondrocyte maturation. }\end{array}$ \\
\hline PAX2 & Probable transcription factor that may have a role in kidney cell differentiation. \\
\hline SOX10 & $\begin{array}{l}\text { This gene encodes a member of the SOX (SRY-related HMG-box) family of transcription factors } \\
\text { involved in the regulation of embryonic development and in the determination of the cell fate. }\end{array}$ \\
\hline SOX17 & Acts as transcription regulator that binds target promoter DNA and bends the DNA. \\
\hline SPIB & $\begin{array}{l}\text { The protein encoded by this gene is a transcriptional activator that binds to } \\
\text { the PU-box (5'-GAGGAA-3') and acts as a lymphoid-specific enhancer. }\end{array}$ \\
\hline SRY & Transcriptional regulator that controls a genetic switch in male development. \\
\hline
\end{tabular}




\section{Continued}

TFAP2A The protein encoded by this gene is a transcription factor that binds the consensus sequence 5'-GCCNNNGGC-3' and activates the transcription of some genes while inhibiting the transcription of others.

TBP General transcription factor that functions at the core of the DNA-binding multiprotein factor TFIID.

USF1 This gene encodes a member of the basic helix-loop-helix leucine zipper family, and can function as a cellular transcription factor.

ZEB1

This gene encodes a zinc finger transcription factor. Acts as a transcriptional repressor. 